\title{
Enabling difficult conversations in the Australian health sector
}

\section{AUTHORS \\ CHRISTINE KING PhD
BRETT WILLIAMS PhD}

\section{CORRESPONDING AUTHOR}

BRETT WILLIAMS Department of Paramedicine, Faculty of Medicine, Nursing and Health Sciences, Monash University, Level 2, Building H, Peninsula Campus. 47-49 Moorooduc Highway, Frankston VIC Australia 3199. Phone: +61 39904 4283. Email: brett.williams@monash.edu
1. Department of Paramedicine, Faculty of Medicine, Nursing Victoria, Australia and Health Sciences, Monash University, Melbourne,

\section{ABSTRACT \\ Background: Research on difficult conversations is mainly about the impacts of avoiding difficult conversations, with little research on enabling difficult conversations except for improving communication.}

Objective: This study aimed to identify the ideal environment for enabling difficult conversations to take place in healthcare settings.

Methods: Convergent Interviewing was used with 20 clinical supervisors to explore the following question: "What enables healthcare professionals in the workplace to have difficult conversations?" Of these 20 clinical supervisors, 10 were nurses, eight were in allied health (five speech pathologists, two physiotherapists, one community support worker) and two were in medicine.

Results: Enabling difficult conversations is complex and requires change at the individual, team, profession, and organisational levels. Enabling these conversations is not as simple as improving communication skills, although effective communication skills are necessary.

Discussion: Other requirements include the desire for someone to want to have a difficult conversation. This relationship exists between the people needing to have the conversation, the physical environment and time required to have the conversation, and also having management, disciplinary and organisational support to engage in difficult conversations.

Conclusion: Enabling difficult conversations between healthcare professionals is a complicated endeavour involving individual, team, profession, and organisational changes. This implies making a significant effort in presenting training and educational opportunities for all health professionals.

What is already known about the topic?

- Poor communication is a key contributor to medical errors.

- While clinical supervisors need to have difficult conversations with peers, patients and managers, many supervisors lack the skills to adequately perform these on a regular basis.

What this paper adds:

- Having difficult conversations between healthcare professionals is complex.

- That focussing on 'enabling' is a more proactive and positive approach than focusing on 'avoiding'.

Keywords: Medical errors, enabling difficult conversations, crucial conversations, clinical supervision, clinical placement, health educators, nursing, allied health personnel. 


\section{INTRODUCTION}

A difficult conversation is defined as a discussion between two or more people where the stakes are high, options vary, and emotions run strong. ${ }^{1}$ It can also be referred to as a crucial conversation. ${ }^{2}$ Research on difficult conversations in the health sector is predominantly related to those between medical professionals and patients.,4 Research on the difficult conversations that take place between healthcare professionals themselves (including students) is comparatively limited but has been linked to medical errors and patient safety. The impact of medical errors in Australia is a concern as is in America and the UK. ${ }^{6,7,10,11}$ One study regarding difficult conversations among peers, colleagues, and students does suggest that broken rules, mistakes, lack of support, incompetence, poor teamwork, disrespect, and micromanagement, represent seven different crucial conversations that need to take place between health professionals, but often do not. ${ }^{2}$ This and other more recent examples illustrate the differences in the skills and culture change required to enable difficult conversations between health professionals themselves compared with those needed between health professionals and patients. ${ }^{13-16}$

Poor communication between health professionals has been well documented. ${ }^{17}$ Poor communication and collaboration can cause burnout and stress in nurses and can harm and even kill patients. ${ }^{2,12}$ Polito states that communication failures are the leading root cause of serious medical errors. ${ }^{19}$ After examining several strategies for managing difficult conversations, Polito came up with six suggestions on how to conduct successful communication during difficult conversations. These included:(i) being prepared by collecting facts and not opinions, (ii) being aware of the purpose of their conversation, (iii) practising having difficult conversations, (iv) managing emotions appropriately, (v) listening and understanding, and (vi) provide feedback and follow-up of communication behaviours. ${ }^{19}$

Today, much of the research on difficult conversations is about the impacts of avoiding difficult conversations, with little research on enabling difficult conversations, except for improving communication. Of this research on improving communication, most are on the communication between the healthcare professional and the patient. But is effective communication the solution to enabling difficult conversations, or is it more complex? This research explores this question from the perspective of clinical supervisors and educators. They interact with a broad range of students as well as peers and colleagues in the health sector. A convergent interview process is used to enable deeper level insights to be gained about the complex phenomenon than traditional interview techniques, to explore the question "What enables healthcare professionals in the workplace to have difficult conversations?"

\section{METHODOLOGY AND METHODS}

\section{DESIGN}

To explore the enabling of difficult conversations, an action research-based interview method known as Convergent Interviewing was used. ${ }^{20}$ This method tests for convergent information and explores divergent information and is based on undertaking a series of paired interviews until the 'saturation of ideas/knowledge' is reached. After each pair of interviews, the interviewer constructs deeper levels of questioning based on this convergence and divergence, and these are added to the initial broad question and any other additional questions from previous cycles (Figure 1).

For example, if the first interviewee of the pair said that the sky was green and the second interviewee of the pair said it was blue (i.e. a difference in data) then a more in-depth level question would be constructed to find out why: "In previous interviews, some people have said the sky was blue, and some said it was green, why do you think there were these differences in perceptions?"

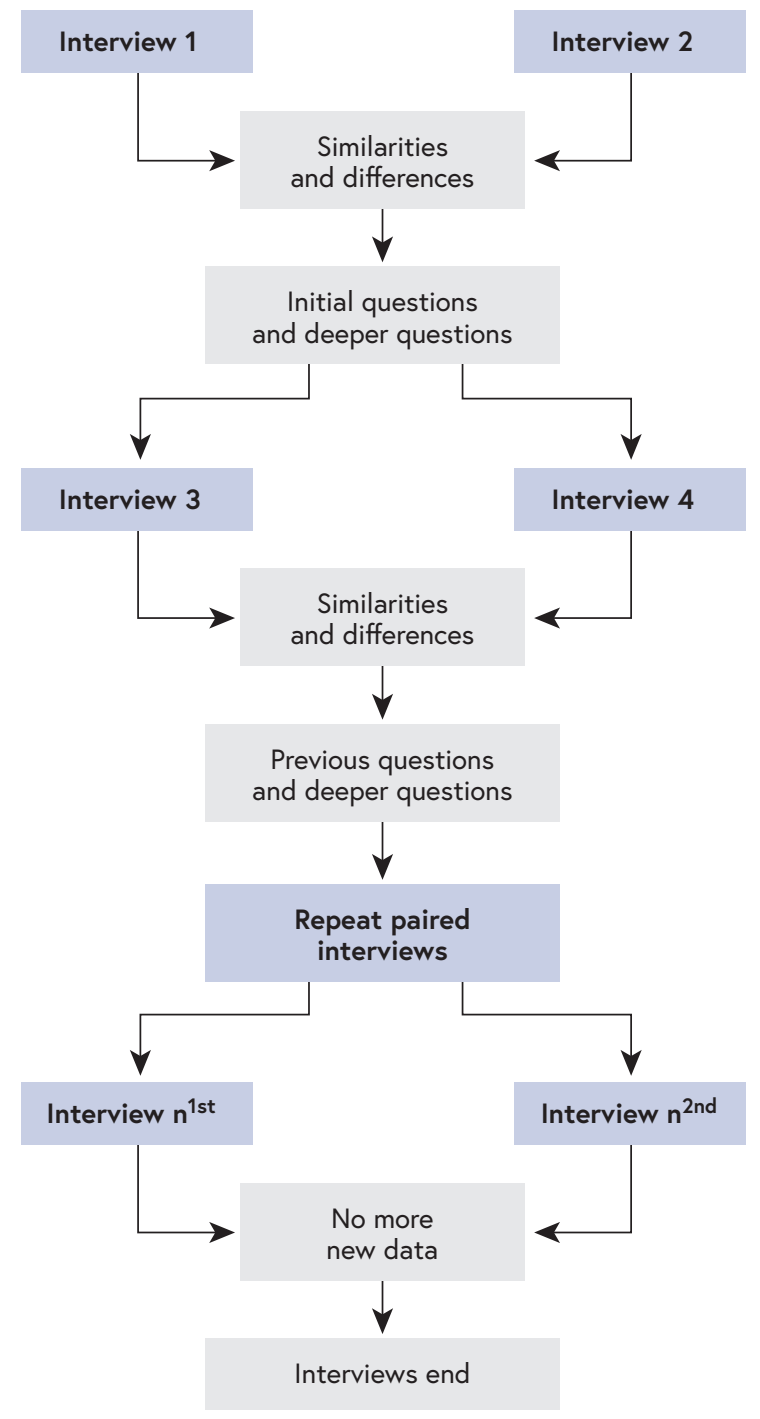

FIGURE 1: THE CONVERGENT INTERVIEWING PROCESS 
However, if both interviewees said the sky was blue (i.e. similarity in data), then a confirming question would be asked: "So far, everyone we have interviewed has said the sky was blue, can you think of any situations where this was not the case?" The deeper level question would then be asked to the next pair of interviewees. Through this deeper level of questioning, themes emerge from the data, and these form the basis of the results.

This method assumes that the interviewer (an outsider) does not have as much knowledge as the interviewees (insiders) about the situation, so is not well equipped to design and develop a list of interview questions. That is, the participant data helped to frame deeper level questions which are not possible with more traditional interview methods. King notes secondary benefits of convergent interviewing, including shared learning in the way in which deeper level questions are asked, and ownership, where participants recognise that the questions being asked are reflective of participants' knowledge and that the interviewer is genuinely listening. ${ }^{21}$

\section{PARTICIPANTS}

The invitations to participate in the study were sent out to 113 clinical supervisors who were past participants of a 'Difficult Conversations' workshop that was run throughout Victoria in nine locations. Forty clinical supervisors responded to the invitation and suggested dates and times that they were available over two weeks. Of these 40, interviews were conducted until the saturation of ideas was reached at 20 interviews. Interviewees were selected based on their availability, and where participants had coinciding times available, the first to respond was provided their preferred interview time. The interview also ensured a cross-section of participants. Further information about the Difficult Conversations workshop can be found in Williams et al, ${ }^{16}$ and king et al. ${ }^{22}$

\section{DATA COLLECTION}

Interviews were carried out over two weeks by phone and each interview took approximately one hour and consisted of two parts. Part A aimed to explore why difficult conversations are avoided in the workplace, and Part B sought to find out what workplace environment is needed to enable difficult conversations. This article reports on Part B and used the open-ended question: "What enables healthcare professionals in the workplace to have difficult conversations?"
Interviews were typed into a word document by the interviewer, as the interview took place. The interviewer (one of the authors) has over 20 years' experience in this type of method and asked questions and prompted and typed responses during the interview. Interviews were also recorded so that the interviewer could fill in any words that were missed immediately after the interview. The findings of Part A are also published and can be found in King et al. ${ }^{22}$

\section{DATA ANALYSIS}

The interviewer spent approximately two hours after each pair of interviews looking for similarities and differences in the data. These were then used to construct new additional questions to be asked to the next pair of interviewees, to confirm, disconfirm, and explore at a deeper level. The time to do this analysis throughout the process had to be factored into the interview schedule. The convergence of the data led to several themes being identified along the way. After the interviews were completed, the interviewer wrote up the emergent themes, referring back to the data to check assumptions, explore further depth for each of the themes, and distil interviewee 'quotes' that could be used to highlight the main themes.

\section{ETHICS}

Ethics approval was received from the relevant health service and the Monash University Human Research Ethics Committee (MUHREC).

\section{RESULTS}

Twenty health professionals took part in the study. Ten were nurses, eight were in allied health (five speech pathologists, two physiotherapists, one community support worker) and two were in medicine. Of these 20 , two were from the private sector, and the remaining 18 were in the public sector. Concerning practice location, there were two rural, eight regional, and eight metropolitan participants. No participants identified as being remotely located. Of the 20 participants, 18 indicated that they had some previous form of training in clinical supervision, with eight indicating formal qualifications in clinical supervision. Table 1 shows the years of experience of participants in the health sector and as a clinical supervisor.

\section{TABLE 1: LENGTH OF EXPERIENCE OF EDUCATORS}

\begin{tabular}{|c|c|c|c|c|c|c|c|}
\hline $\begin{array}{l}\text { Year of } \\
\text { experience }\end{array}$ & Nil & $\begin{array}{l}\text { Less than } \\
1 \text { year }\end{array}$ & $1-4$ years & 5-10 years & $11-15$ years & $16-20$ years & $\begin{array}{c}\text { More than } \\
20 \text { years }\end{array}$ \\
\hline Health sector & 0 & 1 & 3 & 4 & 1 & 2 & 9 \\
\hline
\end{tabular}




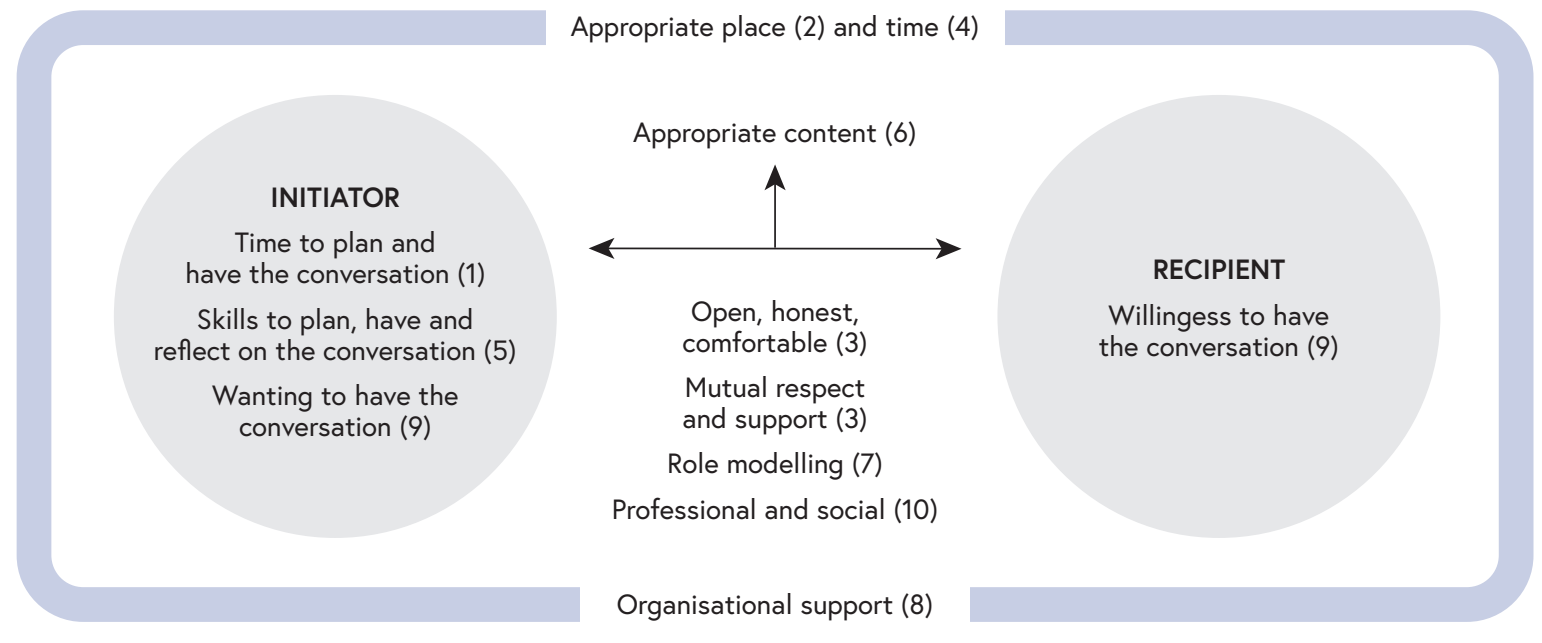

FIGURE 2: THE COMPLEXITY OF ENABLING DIFFICULT CONVERSATIONS

Ten themes emerged from the convergent interviewing process (Figure 2). Each of these is described below. Direct words or quotes of participants are presented in italics.

\section{THEME 1: TIME TO PLAN AND HAVE A DIFFICULT CONVERSATION}

Time was the most frequently cited enabler. As one participant put it, 'To have a difficult conversation, you do need to have time to make a plan, it can't be rushed, or it will be a disaster'. Many of the participants echoed similar opinions. Concerning time, the busy nature within healthcare settings was often mentioned, especially about triage, and 'high paced fast-changing environments', as well as environments where a lot of emotional energy or attention had to be focused on patients, e.g., oncology. Ideally, enabling difficult conversations involves a person having enough time to have the conversation as well as plan the conversation.

\section{THEME 2: AN APPROPRIATE PLACE TO HAVE THIS TYPE OF CONVERSATION}

Almost all participants mentioned having an appropriate place to have the conversation was ideal. They noted that having a safe, private, quiet environment in which such conversations can take place using calm voices is a key factor and one that's often hard to come by in medical settings. Short sharp conversations were noted as being able to be said quietly at the time, e.g. 'not washing your hands' but most difficult conversations needed a quiet private space. Most participants stated that these places were not easily accessible in their workplace, if not there at all; however, a few participants mentioned that their workplaces did have these places and they were seen as necessary.

\section{THEME 3: OPEN, HONEST AND COMFORTABLE RELATIONSHIPS BETWEEN STAFF WHERE THERE ARE MUTUAL RESPECT AND SUPPORT}

Many participants also noted that mutual respect for one another is a vital enabling factor. One particularly stressed the idea of a 'respectful environment where people value one another...not just individual but cultural as well...' Others noted that this respect includes such concepts as privacy and confidentiality, and others mentioned respect to take on board each other's perspectives. Having an environment that encouraged teamwork and provided skills training in teamwork was mentioned by several participants. As one interviewee explained 'when the environment is one of a high-functioning team and where there is respect for each other and conflict is dealt with, these conversations are better able to take place'. It was considered that when both parties feel comfortable, the conversation is much more likely to take place without much trouble. Participants also noted the need for a supportive environment. One participant highlighted the importance of senior staff support by stating, 'Having support from senior staff... having them available to have a pre-conversation with them before you see a student. Having that support is important.'

\section{THEME 4: ENGAGING IN CONVERSATIONS AS SOON AS POSSIBLE AFTER AN ISSUE ARISES, BUT AT AN APPROPRIATE TIME}

Timeliness or being able to address things as they arise was also key. Several participants noted that when issues go unaddressed for days, they tend to grow in some way, and the needed conversation is harder to enact. As one participant put it: '... a lot happens on the fly, and things are left a little longer and escalate where they didn't need to ... being proactive and not reactive...' Another participant wished that all staff were '... empowered enough so that they could have the conversation as the issue arises rather than calling me up four days later.' As another participant stated 'by the time it comes to me, 
and I have to deal with it, it almost becomes hearsay.' The ideal environment would enable people to have a conversation immediately when an issue came up.

\section{THEME 5: THE RIGHT SKILLS IN PLANNING, HAVING AND REFLECTING ON DIFFICULT CONVERSATIONS}

Staff having the skills to engage in difficult conversations was also seen as necessary as these types of conversations were seen as needing much higher levels of skill than everyday conversations. These included skills in planning the conversation, having the conversations, as well as reflecting on the conversations. As one interviewee expressed 'Having the skill is important. Some people have it innately, and others don't. . but it is needed'. Participants mentioned that the 'ideal' environment would enable access to education, training, courses, and workshops to improve the skills of staff having difficult conversations. As one participant described, 'Skill is paramount...one thing we have learned is that being able to practice that skill through training, where you are not being judged... it gives you the confidence to try it in practice. You can address challenges in a safe environment. Training has given me the ability to reflect back on your skills.'

\section{THEME 6: ENSURING APPROPRIATE CONTENT IS DISCUSSED}

Basing conversation on objective facts, with evidence to back up what is being conveyed was seen as very important to participants. In addition to establishing conversations on fact, focusing on the behaviour and not the person was also emphasised as appropriate in terms of the content of a difficult conversation. Many of the participants expressed the need to ensure that the issue being addressed was placed in the bigger picture or concern, for example, the impact on the patient. As one participant noted, 'You need to bring it back to the patient or safety rather than a personal attack ... and you need to let them speak.' Being able to do this in practice was acknowledged as difficult, with participants suggesting that appropriately expressing things was not a skill many people had in both their personal and professional lives.

\section{THEME 7: LEADERS ROLE-MODELLING HAVING THESE TYPES OF CONVERSATIONS}

Participants also felt that role-modelling on the part of leaders and seniors was also necessary for enabling difficult conversations. That is, if junior staff or new staff observed other more senior or long-term staff having and supporting difficult conversations with each other, with junior staff and with staff from different disciplines, they would also be more likely to have these conversations themselves and see this as part of the culture. As one participant put it, 'Leadership and management lead the way... role modelling... strong leadership that models openness and shows how it [difficult conversations] is done in a professional way... if it is seen in the culture... more people will come forward and not hold back if they know it will be dealt with properly..." Another participant stated, 'If you have good role models and modeling of skills to junior staff when you are having these conversations... they will learn skills as well.'

\section{THEME 8: ORGANISATIONAL SUPPORT AND OPTIONAL MEDIATION}

Another factor mentioned by participants was having an organisational mandate or expectation for difficult conversations to take place. Some of the participants felt that if difficult conversations were advertised or expressed as part of the corporate mandate, then people would be obliged to engage in these conversations. As one participant described, 'Even if it's not a written company policy, it can still be a clearly communicated expectation'. Mediation was also mentioned as something that organisations could provide. It was expressed that difficult conversations can quickly spiral out of control, resulting in negative consequences for both parties. Having a mediator present can help diffuse tension and keep things on track. As one participant noted, '...if things deteriorate you need someone else ... they can call a halt to things before the situation becomes unsalvageable.' This was seen as particularly important when conversations had to take place across hierarchical levels.

\section{THEME 9: WANTING TO HAVE THE CONVERSATION COMPARED TO TIME AND SKILL}

When participants were asked which was the most important, time or skill; almost all participants stated that skill was more important than time. This was an interesting finding, as when participants were asked the general question of what the 'ideal' qualities were, participants mentioned time before they mentioned skill. As one person noted, 'There is always time ... I know from being in the coal face ... time is a copout excuse ... if you really have to have that conversation you create time ... skills you cannot pull out of the air.' Another person also said, 'I go with skills rather than time ... if they say they don't have time they are probably avoiding it. Skill level is a whole different ball game. If you don't have the skill you could make the situation worse by having a difficult conversation. If you have a skill, you can usually make it a positive outcome.' In terms of skill, the benefits of training and role modelling were emphasised.

Although skills were seen as more influential than time, many participants expressed that wanting to have the conversation was more important than skill or time. For example, 'Skill will help your communication, but it is whether you want to talk to them or not. If the person doesn't want to listen, then it won't work either. I can teach people with different personalities ... but if it's a nasty person you have to have the conversation with ... you suffer.' In terms of time, one participant stated, 'Time is not the main issue. As long as you want to solve the problem, you will find the time. In the health system, it can be busy; however, it depends on how much you want to'. 


\section{THEME 10: CONVERSATIONS ARE MORE LIKELY TO BE HAD IF THE RELATIONSHIP BETWEEN HEALTHCARE PROFESSIONALS IS BOTH PROFESSIONAL AND SOCIAL}

Navigating the boundary between social relationships and professional relationships was seen as a tricky business for many of the participants. The majority of participants suggested that there 'needs to be a happy medium' between or ' $a$ mix of both' professional relationships and social relationships. Still, when you are at work, relationships need to be professional. This was seen as more of an issue in small organisations and rural areas. For example, 'It is important to have a social relationship with what you do particularly with nurses on the ward - so getting to know each other well makes it easier for us to work together... so hopefully it doesn't come to the difficult conversation with them. Might come up to you informally - someone coming to you and saying I am not so confident in doing this.' As one participant stated, 'You don't need to be socially hanging out, but there needs to be a genuine investment in a person, i.e. what did you do on your weekend ... this helps with people take on board feedback because they feel built up and affirmed ... and you show you want to connect.' Participants felt that there must necessarily be a bit more distance if you were in a management position to be able to manage people professionally objectively, but that this does not preclude being personable to some degree.

The ten themes show the complexity of enabling difficult conversations. When a systems approach is taken, four system levels need to be considered: the components, the interaction between the components, the emergent properties of this interaction, and the broader system (i.e. context) that these are all embedded in. Figure 2 is a systems model of the themes that emerged in this study. These levels are useful in identifying what is needed at different system levels to enable difficult conversations and identify where changes can be made at these levels.

\section{DISCUSSION}

The study showed that difficult conversations could be enabled in a variety of ways. These are not just about communication, but also the desire for someone to want to have the difficult conversation, the relationship that exists between the people needing to have the conversation, the physical environment and time required to have the conversation, and also having management and organisational support to engage in difficult conversations. The findings can be compared with other studies in the literature. For example, Stans et al recommend that it is essential for healthcare professionals to have an overall awareness of the potential influence of environmental elements on conversations. ${ }^{23}$ In a recent study, ${ }^{14}$ nine themes emerged (using a grounded theory method) about the aspects of team communication from the perceptions of interprofessional PCMH team members, and these were shared knowledge, situation/goal awareness, problemsolving, mutual respect; and communication that is transparent, timely, frequent, consistent, and parsimonious (concise). Our findings were also congruent with three of the AACN Standards for establishing and sustaining healthy work environments, including skilled communication, true collaboration, and authentic leadership. ${ }^{24}$

In the widely recognised SPIKES six-step protocol for delivering bad medical news, ${ }^{3}$ the first critical item to address is the setting. Although the difficult conversations medical professionals often have with patients are very different from the kinds of difficult conversations that need to occur between health sector peers, colleagues, and students, this is one area where the two show significant overlap. In considering the setting for a difficult provider/ patient conversation, the SPIKES protocol highlights the need for reserving adequate time for the conversation as well as adequate privacy. ${ }^{3}$ However, when the setting can't be controlled, such as an imminent mistake in the context of delivering care, the ideal environment includes one's ability and willingness to speak up both immediately and as discreetly as possible. In a study of nurses who do and don't speak up in such acute situations, Maxfield, Grenny, Lavandero \& Groah suggest that critical factors included a positive culture where physicians accept or encourage nurses to speak up and speaking up in a discreet way that allows the caregiver to "save face". ${ }^{12}$ Ulrich suggest that to enable difficult conversations three things need to be carried out (i) identifying the communication that is required, (ii) instilling confidence in healthcare professionals to have difficult conversations, and (iii) create work environments where having difficult conversations is valued. ${ }^{25,26}$

To borrow from psychology, where clinical training encompasses many of the same barriers to engaging in difficult conversations as are experienced in health sector clinical supervision educators need an integrated set of skills, and attitudes to have productive difficult conversations associated with functional competency domains. ${ }^{27}$ The same can also be applied to difficult conversations between peers and colleagues in the health sector, and specifically applied beyond competency to the seven crucial conversations identified earlier. Obvious skillsets include giving and receiving quality feedback. A less obvious skillset is acquiring a higher level of insight regarding one's skills, behaviours, and attitudes, which is an especially difficult undertaking when the lack of understanding is combined with incompetence. ${ }^{28}$ The role of self-monitoring and self-reflection has been noted elsewhere. ${ }^{13}$ This highlights the importance of 'enabling' being seen as a process or a series of difficult conversations that can be reflected upon enabling learning to take place. In addition to skill-building, is an understanding of the complexity involved in different health settings and the impact this has on enabling difficult conversations. For example, it could be argued that not 
everyone is eligible to have these conversations, for example, not everyone is involved in medical error 'debriefings'. Hierarchical issues and issues that occur across disciplines also make this more complex. For example, it is commonly reported in nursing practice, that it is difficult for nurses to give critical feedback to doctors about care and for nurses to provide feedback to management on issues regarding workload. $2,12,29$

When teams can mindfully engage in and conduct crucial conversations, they thrive. $3^{\circ}$ In contrast, when they cannot engage in difficult conversations, it can result in high rates of avoidable medical errors. In 2005 the number of patients estimated to have died from mistakes made while they were in hospitals in the US alone was more than 195,000 although more recent studies report it to be as high as 400,000 per year and the third largest cause of death. ${ }^{2,15} \mathrm{~A}$ portion of those deaths could be avoided if health sector employees were willing and able to have the crucial difficult conversations that should happen around broken rules, mistakes, lack of support, incompetence, poor teamwork, disrespect, and micromanagement. ${ }^{2}$ Within this high-stakes framework, engaging in a difficult conversation becomes an ethical responsibility. ${ }^{27}$ It may also help to reassure people that feeling apprehensive about a difficult conversation is perfectly natural because the outcome is uncertain, which is why courage (acting despite apprehension) is needed to make it happen..$^{31}$ All of this will require training and focussing on how to facilitate learning about the skills required. Kim et al, suggest that future work could focus on understanding how to teach and sustain effective parsimonious communication, with strategies such as team communication training, information, and communication technologies, and using standardised communication tools. ${ }^{14}$ We agree, and add that this needs to be carried out at all levels, and also needs to include additional training in the more systemic factors that have emerged through this study.

Concerning the change required in the health sector, there are two distinct changes needed to enable difficult conversations and move towards a culture of safety. The first is to overcome the various reasons for avoiding the difficult conversations altogether, and, second, to ensure that when difficult conversations do happen, they are executed effectively, which necessarily involves equipping people with the skills needed to do so, including both effective communication as well as other requirements at different system levels. To address these, we suggest, clinical educators particularly, using different types of learning depending on the changes needed, particularly single, double, and tripleloop learning. ${ }^{22}$ Single-loop learning is focused on correcting errors by changing routine behaviour. Double-loop learning, however, corrects errors by examining the underlying values and policies within an organisation. Triple loop learning, also referred to as deutero learning, includes designing norms and protocols that govern single and double-loop learning. ${ }^{33}$
Groot and Maarleveld point out that it is important to note that one loop is not more important than another. In some situations, single-loop learning suffices (such as in the change of rules and procedures). Still, in other cases, double and triple-loop learning is required (a radical transition or innovation). Groot and Maarleveld provide a useful table for looking at the implications for the facilitation of the three learning loops (Table 2). ${ }^{33}$

\section{TABLE 2: DIFFERENT IMPLICATIONS FOR FACILITATION OF THE THREE LEARNING LOOPS ${ }^{33}$}

\begin{tabular}{|c|c|c|}
\hline $\begin{array}{l}\text { Improving (single } \\
\text { loop learning) }\end{array}$ & $\begin{array}{l}\text { Renewing: double } \\
\text { loop learning }\end{array}$ & Triple loop learning \\
\hline $\begin{array}{l}\text { Facilitation focuses } \\
\text { on learning about } \\
\text { rules and regulations }\end{array}$ & $\begin{array}{l}\text { Facilitation focuses } \\
\text { on the underlying } \\
\text { assumptions of } \\
\text { the rules and } \\
\text { regulations. }\end{array}$ & $\begin{array}{l}\text { Facilitation focuses } \\
\text { on underlying } \\
\text { paradigms, } \\
\text { objectives, norms } \\
\text { and values. } \\
\text { Facilitation focuses } \\
\text { on learning about } \\
\text { single and double } \\
\text { loop learning }\end{array}$ \\
\hline $\begin{array}{l}\text { Facilitation focuses } \\
\text { on how questions: } \\
\text { how to improve, how } \\
\text { to avoid failures? }\end{array}$ & $\begin{array}{l}\text { Facilitation focuses } \\
\text { on the why } \\
\text { questions: why do } \\
\text { existing practices, } \\
\text { rules and regulations } \\
\text { exist? }\end{array}$ & $\begin{array}{l}\text { Facilitation focuses } \\
\text { on the underlying } \\
\text { why questions: } \\
\text { why do we have } \\
\text { the insights that } \\
\text { underpin our routine } \\
\text { as we have them? } \\
\text { Why these goals? }\end{array}$ \\
\hline $\begin{array}{l}\text { Facilitation focus } \\
\text { on obligation and } \\
\text { permission }\end{array}$ & $\begin{array}{l}\text { Facilitation focuses } \\
\text { on knowing and } \\
\text { understanding }\end{array}$ & $\begin{array}{l}\text { Facilitation focus on } \\
\text { will and being }\end{array}$ \\
\hline $\begin{array}{l}\text { Evolutionary, } \\
\text { incremental }\end{array}$ & $\begin{array}{l}\text { Revolutionary, } \\
\text { concerned with } \\
\text { conflicts and } \\
\text { disputes }\end{array}$ & $\begin{array}{l}\text { Revolutionary, } \\
\text { concerned with } \\
\text { conflicts and } \\
\text { disputes }\end{array}$ \\
\hline $\begin{array}{l}\text { Increasing efficiency } \\
\text { and effectiveness/do } \\
\text { the things right }\end{array}$ & $\begin{array}{l}\text { Renewing/do the } \\
\text { right things }\end{array}$ & Development \\
\hline
\end{tabular}

Along with those rational and moral arguments in favour of having difficult conversations, a big-picture effort might involve an organisational culture change effort to establish an environment more conducive to having difficult conversations, one where people are encouraged to speak up when something is amiss. This may involve moving a hospital or other clinical setting from an aggressive/defensive culture (opposition to new ideas, competitiveness, independently competent, protective of individual status and security) to a more constructive culture (cooperation, collaboration, teamwork-oriented, participative decision-making) as can be measured using a tool such as the Organisational Culture Inventory. ${ }^{34}$ In the Difficult Conversations workshops we used a simple process of asking participants' What if I do?' and 'What if I don't?' in terms of having a difficult conversation. ${ }^{16}$ In this process, participants discovered that the negative consequences of not having the conversation far outweighed the negative effects of having the conversation. In this workshop, participants also had the opportunity to 
practice difficult conversations. As a result of our workshop, $75 \%$ of participants reported changes in behaviour about having difficult conversations. Also, interesting to note, was that participants in these workshops saw a need for all healthcare staff to be involved in similar training.

\section{LIMITATIONS}

Qualitative results are not typically generalisable or transferable. The study only involved 20 clinical supervisors and as such, can be considered small, as well as time and space bound. Also, the qualitative nature of this study leaves the results not easily transferable, generalisable, or applied across multiple contexts. Another limitation is that the results did not actively compare across professions. There is an opportunity to carry out a similar study later to focus on different professions to gain more depth or see differences between professions.

\section{CONCLUSIONS}

Understanding the depth and complexity of enabling difficult conversations was easily explored using the convergent interviewing method. It also allowed for some surprises to emerge, such as, the desire to have a conversation having more of an influence on enabling difficult conversations than time or skills. This highlights the need for specific training that links engaging in difficult conversations to reductions in medical errors and deaths. Comparing the findings of this study with other research, this study provided a more systemic view of enabling difficult conversations than previous studies that have used methods that have brought forward findings within system levels. Our findings are relevant across health professions and particularly important to nursing practice. In conclusion, we would like to put forward that although focussing on 'enabling' is a more proactive and positive approach than focusing on 'avoiding', understanding both provides a comprehensive understanding that can be used for future education and training content, design and approach in addressing difficult conversations.

Conflicts of interest: The authors have declared no conflict of interest.

Funding: We would like to thank and acknowledge the Department of Health, Victorian Government, for their funding to undertake this study.

\section{REFERENCES}

1. Varner JM. Difficult conversations. The Alabama Nurse. 2011; 38(4): 3. Available from: https://doi. org/10.4324/9780203050460-14

2. Maxfield D, Grenny J, McMillan R, Patterson K, Switzler A. Silence kills: The seven crucial conversations for healthcare. VitalSmarts. 2005.

3. Davenport L, Schopp G. Breaking bad news: Communication skills for difficult conversations. JAAPA. 2011; 24(2): 46-50. Available from: https://doi.org/10.1097/01720610-201102000_00008

4. Lamiani G, Barello S, Browning DM, Vegni E, Meyer EC. Uncovering and validating clinicians' experiential knowledge when facing difficult conversations: a cross-cultural perspective. Patient Educ Couns. 2012; 87(3): 307-12. Available from: https://doi.org/10.1016/j.pec.2011.11.012

5. Meyer EC. Courage, brains and heart: lessons from the Wizard of $\mathrm{Oz}$ for difficult healthcare conversations. Aust Crit Care. 2014; 27(3): 108-9. Available from: https://doi.org/10.1016/j. aucc.2014.03.002

6. Richardson J, McKie J. Reducing the incidence of adverse events in Australian hospitals: an expert panel evaluation of some proposals. Research Paper 2007 (19); Centre for Health Program Evaluation, Monash University, Melbourne. 2007.

7. Wilson RM, Van Der Weyden MB. The safety of Australian healthcare: 10 years after QAHCS. Med J Aust. 2005; 182(6): 260. Available from: https://doi.org/10.5694/j.1326-5377.2005. tb06694.x

8. Wilson RM, Harrison BT, Gibberd RW, Hamilton JD. An analysis of the causes of adverse events from the Quality in Australian Health Care Study. Med J Aust. 1999; 170(9): 411. Available from: https://doi.org/10.5694/j.1326-5377.1999.tb127814.x

9. Wilson RM, Runciman WB, Gibberd RW, Harrison BT, Newby L, Hamilton JD. The Quality in Australian Health Care Study. Med J Aust. 1995; 163: 458-71. Available from: https://doi. org/10.5694/j.1326-5377.1995.tb124691.x

10. Kalra J, Kalra N, Baniak N. Medical error, disclosure and patient safety: a global view of quality care. Clin Biochem. 2013; 46(13-14): 1161-9. Available from: https://doi.org/10.1016/j. clinbiochem.2013.03.025

11. Waring JJ. Beyond blame: cultural barriers to medical incident reporting. Soc Sci Med. 2005; 60(9): 1927-35. Available from: https://doi.org/10.1016/j.socscimed.2004.08.055

12. Maxfield D, Grenny J, Lavandero R. The Silent Treatment: Why Safety Tools and Checklists Aren't Enough. Patient Safety \& Quality Healthcare. 2011(September/October).

13. Cheng A, Ladonna K, Cristancho S, Ng S. Navigating difficult conversations: the role of self-monitoring and reflectionin-action. Med Educ. 2017; 51(12): 1220-31. Available from: https://doi.org/10.1111/medu.13448

14. Kim LY, Giannitrapani KF, Huynh AK, Ganz DA, Hamilton AB, Yano EM, et al. What makes team communication effective: a qualitative analysis of interprofessional primary care team members' perspectives. J Interprof Care. 2019;33(6):836-8. Available from: https://doi.org/10.1080/13561820.2019.157780 9

15. Makary MA, Daniel M. Medical error-the third leading cause of death in the US. BMJ. 2016;353. Available from: https:// doi.org/10.1136/bmj.i2139 
16. Williams B, King C, Edlington T. Overcoming difficult conversations in clinical supervision. J Healthc Leadersh. 2016;8:31-40. Available from: https://doi.org/10.2147/JHL. $\underline{596592}$

17. Beaumont $\mathrm{D}$. The interaction between general practitioners and occupational health professionals in relation to rehabilitation for work: a Delphi study. Occup Med. 2003: 249-53. Available from: https://doi.org/10.1093/occmed/kqg066

18. Sawney $P$, Challenor J. Poor communication between health professionals is a barrier to rehabilitation. Occup Med. 2003; 53(4): 246-8.

19. Polito JM. Effective Communication during Difficult Conversations. The Neurodiagn J. 2013; 53(2): 142-52. Available from: https://doi.org/10.1080/21646821.2013.11079899

20. Dick B. What can grounded theorists and action researchers learn from each other. The SAGE handbook of grounded theory. 2007; 398-416.

21. King CA. Systemic processes for facilitating social learning. Challenging the legacy. Acta Universitatis Agriculturae SueciaeAgraria. 2000; (233).

22. King C, Edlington T, Williams B. The' Ideal' Clinical Supervision Environment in Nursing and Allied Health. J Multidiscip Healthc. 2020. Available from: https://doi.org/10.2147/JMDH.S239559

23. Stans SEA, Dalemans RJP, de Witte LP, Smeets HWH, Beurskens AJ. The role of the physical environment in conversations between people who are communication vulnerable and healthcare professionals: a scoping review. Disabil Rehabil. 2017;39(25):2594-605. Available from: https://doi.org/10.1080 109638288.2016.1239769

24. American Association of Critical-Care N. AACN standards for establishing and sustaining healthy work environments: a journey to excellence. Am J Crit Care. 2005: 187-97. Available from: https://doi.org/10.4037/ajcc2005.14.3.187

25. Ulrich B. Improving Communications Yields Positive Results. Nephrol Nurs J. 2007; 34(3): 265.

26. Ulrich B. Engaging in Crucial Conversations. Nephrol Nurs J. 2009; 36(6): 583

27. Jacobs SC, Huprich SK, Grus CL, Cage EA, Elman NS, Forrest $L$, et al. Trainees with professional competency problems: preparing trainers for difficult but necessary conversations. Train Educ Prof Psychol. 2011; 5(3): 175-84. Available from: https://doi.org/10.1037/a0029952

28. Ehrlinger J, Johnson K, Banner M, Dunning D, Kruger J. Why the unskilled are unaware: Further explorations of (absent) self-insight among the incompetent. Organ Behav Hum Decis Process. 2008; 105(1): 98-121. Available from: https://doi. org/10.1016/j.obhdp.2007.05.002

29. Ross C, Rogers C, King C. Safety culture and an invisisble nursing workload. Collegian. 2019; 26(1): 1-7. Available from: https://doi.org/10.1016/j.colegn.2018.02.002

30. Karre I. Leading teams that thrive. Curr Opin Gynecol Obstet. 2012; 24(6): 440-4. Available from: https://doi.org/10.1097/ GCO.0b013e328359f061

31. Ferguson D. The art of conversation?: diffusing destructive staff dynamics. Teacher: The National Education Magazine. 2010 (Mar 2010): 16-9.

32. King C, Williams B, Edlington T. Avoiding difficult conversations in the Australian health sector. SAGE Open Nurs. 2020; 20: 1-20. Available from: https://doi. org/10.1177/2377960820941978
33. Groot A, Maarleveld M. Demystifying facilitation in participatory interventions. Wageningen Agricultural University: Department of Communication and Innovation Studies; 1999.

34. Callen JL, Braithwaite J, Westbrook JI. Cultures in hospitals and their influence on attitudes to, and satisfaction with, the use of clinical information systems. Soc Sci Med. 2007; 65(3): 635-9. Available from: https://doi.org/10.1016/j. socscimed.2007.03.053 